\title{
Ambiguity, Multiple Streams, and EU Policy
}

\author{
Robert Ackrill, Adrian Kay and Nikolaos Zahariadis
}

Abstract: The multiple streams framework draws insight from interactions between agency and institutions to explore the impact of context, time, and meaning on policy change and to assess the institutional and issue complexities permeating the European Union (EU) policy process. The authors specify the assumptions and structure of the framework and review studies that have adapted it to reflect more fully EU decision-making processes. The nature of policy entrepreneurship and policy windows are assessed to identify areas of improvement. Finally, the authors sketch out a research agenda that refines the logic of political manipulation which permeates the lens and the institutional complexity which frames the EU policy process.

Keywords: Ambiguity, complexity, policy entrepreneurship, policy windows, multiple streams 


\section{Introduction}

The Multiple Streams Framework (MSF) is a lens that was developed to explain US policy under conditions of ambiguity. It draws insight from interactions between agency and institutions to explain how the policy process works in 'organized anarchies', where there is a shifting roster of participants, opaque technologies, and individuals with unclear preferences. Unlike previous reviews (Zahariadis 2007), we focus only on European Union (EU) adaptations to highlight the institutional and issue complexity of the EU context and the value-added from extending policy applications above the national level. What makes MSF particularly useful at the EU level is that it takes into account what are normally considered to be pathologies of the EU system, such as institutional fluidity, jurisdictional overlap, endemic political conflict, policy entrepreneurship, and varying time cycles. We show how the lens's focus on context and agency productively explains the complex interactions among EU institutions, issues, and policy entrepreneurs, but we also go beyond Zahariadis (2008) to stress the need for further clarification of testable hypotheses and the role of policy entrepreneurship.

The assumptions and structure of the framework are first specified. Applications in the EU context are then reviewed, outlining strengths and limitations. Finally, we chart a course for future research by pointing attention to valuable insight acquired by blending the MSF with neo-institutional approaches of EU policy.

\section{Assumptions and structure}

In contrast to models of rational behaviour, the MSF accords significance to context and time - the latter being a scarce and valuable resource of policy makers, whose primary concern is time, rather than task, management. Instead of choosing 
issues to solve, policy makers are often forced to address a 'multitude of problems that are thrust upon them by factors beyond their control' (Kingdon 1995: 75). The MSF explores which issues get attention and when, how and which actors are mobilized to participate in a given choice opportunity, how issues are framed and meaning generated, and how the process is politically manipulated by skilled policy entrepreneurs. We use EU examples to illustrate the points made.

The lens makes three assumptions. First, policy makers operate under significant and varying time constraints. In practice this means a. they cannot attend to all problems, b. they must use heuristics to get things done, and c. they must accept outcomes that satisfice rather than optimize. Second, means and ends, solutions and problems are generated independently of each other. The implication is that information is vague, consequences are uncertain, and 'there appears to be no satisfactory way of determining an appropriate set of means or ends that would obtain sufficient agreement among a diverse set of stakeholders' (Alpaslan and Mitroff 2011: 23). Political conflict is endemic and issues are frequently settled by activating certain frames as EU actors move in and out of the process. Third, ambiguity permeates the process. Most actor preferences are opaque and not well defined; organizational technology is only partially comprehensible; participation is fluid. Information and institutions are not value-neutral. As a result, the process is open to political manipulation biased in favour of those who generate information, control access to policy venues, and synchronize or exploit group, national, and institutional timetables.

MSF distinguishes between the world of organized anarchy and that of rationality. The MSF does not propose that individuals are acting in a manner inconsistent with their judgment of the best outcome. Adopting a system's point of view, it notes the system is not one of full information, clear goals, and exact 
knowledge of the process. Indeed, policy makers 'appear to be comfortable with an extraordinary array of [conflicting preferences and] unreconciled sources of legitimate wants' (March 1978: 599). In such a world no one controls the linkage between individual inputs and policy outputs. Rather ambiguity and randomness are part of normal EU policy-making and not pathologies that need to be rectified.

The lens contains five structural elements: problems, policies, politics (the three streams of the MSF), windows of opportunity, and policy entrepreneurs. The analytical task is to specify the dynamic and complex interactions that generate specific policy outcomes. Problems constitute conditions, measured by indicators often thrust into salience by focusing events (Birkland 1997), that policy makers, interest groups, and other policy actors believe warrant attention. Rapidly deteriorating public finances in Greece, bank implosions in Ireland and political conflict in Georgia are all problems that may warrant policy maker attention. Policies are ideas or solutions that specialists develop to address pressing problems. Domestic fiscal reforms combined with external assistance to allow Greece to continue financing its sovereign debt and mediation in the Georgia conflict are solutions to problems of the day. Politics constitutes the broader environment within which policy is made. The ideological proclivity of incoming governments in EU capitals, the political muscle of bank lobbies in Brussels, and the partisan balance of power in the European Parliament constitute elements of the political stream.

Policy windows open in the politics or problem streams and describe the particular context within which issues are debated and policies made. They constitute triggers that delimit and/or help frame the way issues are debated. For example, the Madrid and London bombings in 2004 and 2005 ushered in new policies and a different attitude toward terrorism. Policy entrepreneurs are skilled and resourceful 
actors who couple the three streams together - problems, policies, and politics during open policy windows. Entrepreneurs are an important part of the process because policy is often not made in a rational, linear manner. In the presence of ambiguity of information and issue complexity, entrepreneurs craft contestable meaning, which they in turn disseminate to policy makers in order to activate attention and mobilize support or opposition.

For example, the decision to bail out Greece involves far more than a costbenefit analysis of Greek public finances. It is fundamentally a question of credibility, confidence, trust, and faith - EU credibility in the eyes of investors and taxpayers, confidence in Greek ability to implement painful reforms, voter trust in German leadership, and faith in the euro. Moreover, to gain political traction a successful bailout depends vitally on framing reforms as promoting growth rather than imposing austerity. Entrepreneurs may be Commission officials by virtue of privileged position in EU information networks, prominent national policy makers, high-level members of other EU institutions, or well-connected non-governmental organization (NGO) actors with a stake in EU policy.

Coupling is a major aspect of the MSF. Apart from skills and resources, entrepreneurs pursue strategies to join together problems and policies into attractive packages, which are then 'sold' to receptive policy makers. The panoply of strategies includes appeals to higher-order national or EU symbols, framing as loss or gain, affect priming through mass arousal of public sentiment, and salami tactics. For example, as long as the problem remained framed as sinking Greek finances, EU policy makers were collectively reluctant to assist Greece pay back its debt to private (ironically mostly EU) creditors. It was only after the risk of contagion threatened to 
engulf their own economies that aid 'to save the euro' became possible (Zahariadis 2012).

Taking the lens beyond the national level clearly demonstrates the need to specify how time cycles (Goetz 2009) also affect coupling. The short-term feedback from financial markets stands in stark contrast to long-term political calculations by national policy makers. To take another example, the beginning of EU budget negotiations opens policy windows for a wide range of issues to be addressed. Paying attention to these negotiations depends partly on national electoral timetables, making coordination a crucial component of coupling. Policy entrepreneurs must straddle not only national but also EU institutional venues in ways that maintain domestic political support and still cultivate robustness of appeal to diverse audiences. The complexity of EU institutions serves as a valuable laboratory in which to test the conditions under which strategies of political manipulation work. The next section critically reviews those efforts.

\section{A review of applications in the $\mathrm{EU}$ context}

This section considers the uses to which the MSF has been put in academic writings. There is an extensive body of work which references Kingdon, frequently in the context of identifying individual elements of the MSF relevant as background to those papers (examples include the concept of the policy entrepreneur, windows of opportunity for policy-making, sometimes concepts as broad as agenda-setting), but without applying the ideas directly. A rather smaller number of articles draw on individual elements of the MSF in their own analyses. Fewer still apply what one might call the 'full' MSF to EU policy analysis. 
In this section, we begin with a very brief overview of the origins of the MSF. After this, a small sample of papers is presented to illustrate how elements of the MSF have been utilised, but without the full model being called upon. This is followed by a fuller consideration of the key articles which have applied the MSF to EU issues. As we shall see, the first set of partial applications, which focus principally on agendasetting, tend to come before the publication of Zahariadis (2003). The work of Zahariadis (notably 2003; 2008) marks a shift in the literature. By presenting arguments for two notable developments in the MSF, to analyse decision-making as well as agenda-setting; and to adapt the MSF to accommodate EU decision-making specificities, the foundation was laid for much of the empirical work which followed, and which is explored below.

The starting point for the MSF, however, is Cohen et al (1972). This analysis of "organized anarchies" (universities, specifically) looked at organizational choice in the presence of problematic preferences, unclear technology and fluid participation. They argue (on page 2) that 'one can view a choice opportunity as a garbage can into which various kinds of problems and policies are dumped by participants as they are generated.' They go on to say (on pages 2-3) that 'a decision is an outcome or interpretation of several relatively independent streams within an organization.' They identify four streams: problems, solutions, participants and choice opportunities. 'The garbage can process is one in which problems, solutions, and participants move from one choice opportunity to another' (page 16). Kingdon (1995: 86) follows the "general logic" of Cohen et al, but from his research into United States' (US) federal health and transportation policies, identifies three streams - problems, policies and politics. 
In 2001, Johan Olsen identified the EUS as 'an obvious candidate' for study using a garbage can approach (Olsen 2001: 196). He also stated that 'it may also be necessary to accept that significant political phenomena sometimes are complex enough to make any simpler theory of them unsatisfactory' (ibid), which could be taken as a clarion call to which this collection, offering multiple approaches, is a response (see also Winn, 1998).

Turning to some of the literature referencing the work of Kingdon, we begin with a sample of papers which highlight some of the constituent concepts used by academics, without their utilising the full MSF. The implication of this is that these are concepts, embodied in the MSF, which are seen more widely as having particular relevance and importance in policy analysis. Examples include the (implicit) referencing of windows of opportunity and (policy) entrepreneurial activity (Cram 2001; see inter alia, page 777). Policy entrepreneurs and entrepreneurship are also hinted at by Ringe (2005), in his analysis of the functioning of the European Parliament. His work also emphasises both ambiguity and institutions (see also Corbett, 2005: 153). Princen (2007), meanwhile, references Kingdon in the context of agenda-setting.

Early papers which utilise the MSF more fully in their analyses include, notably, Pollack 1997; Nugent and Saurugger 2002; Krause 2003; and Jordan et al 2003. Krause 2003, and later, Corbett, consider ambiguity as being a result of the institutional nature of the EU. Within that institutional structure, the Commission is often seen in these earlier contributions as a policy entrepreneur but, consistent with an agenda-setting view of the MSF, is not a part of the decision-making process. Nor is the Commission able to open a window of opportunity, but must wait for one to open. 
One particular dimension of institutional structure in the EU which creates ambiguity is its multi-level nature (see also the contribution by Stephenson 2013 <THIS ISSUE: PUBLISHER TO ADD/UPDATE DETAILS AT PROOF>). Specifically, the Commission's role as policy entrepreneur 'seems to depend largely on member state uncertainty regarding the problems and policies confronting them and on the Commission's acuity in identifying problems and policies that can rally the necessary consensus among member states in search of solutions to their policy problems' (Pollack 1997: 128; see also Jordan et al 2003). The role of the Commission as policy entrepreneur within the Politics Stream is an important part of the work of Nowak (2010). He compares two legal cases, Dassonville and Cassis de Dijon, through Kingdon's multiple streams lens. He identifies why, whilst these cases raised essentially the same legal issue in European Court of Justice rulings, the latter case resulted in the development of the policy concept of mutual recognition in intraEU trade, a central concept in developing the Single European Market. Importantly, he distinguishes clearly what was lacking in the first case to prevent this policy development at that time.

The character of the window of opportunity also receives brief treatment. It has been argued that the opening of a window of opportunity, 'is not so much an active agent [of change] itself but rather a facilitator for the independent variables' (Nugent and Saurugger 2002: 349). These authors, drawing on Keeler (1993), also suggest that the wider the open window, the greater the possible change - with unpredictable events opening the window wider (an idea returned to below).

Turning to the more recent literature, Eberlein and Radaelli (2010), and Borrás and Radaelli (2011), along with Corbett (2005), are of particular interest as they not only use the MSF, but do so in conjunction with other analytical frameworks. Borrás 
and Radaelli embed (historical and discursive) institutionalism within the MSF (something Ackrill and Kay (2011) also do, albeit implicitly). Corbett explicitly draws on the work of Baumgartner and Jones (1993) to illuminate issue-definition and venue; and March (1994) to further the analysis of decision processes.

The aforementioned papers, however, typically adopt the MSF without adaptation to the specifics of EU policy processes. The nature and sources of ambiguity need to be defined clearly, partly as a result of which policy spillovers may not be of the type described by Kingdon, for whom a demonstration effect saw policy ideas copied in different policy arenas. Such institutional ambiguity may result in direct spillovers between linked policy arenas. Do these spillovers, in turn, affect the nature of the opening of a window?

The role of specific policy entrepreneurs needs careful delineation from the broader process of policy entrepreneurship (see, inter alia, Mintrom and Norman 2009; Ackrill and Kay 2011). Further, given the frequent identification in the extant literature of 'the Commission' (usually as a singular entity) as a policy entrepreneur, this challenges the idea of entrepreneurs being located outside of decision-making processes (although such an idea is consistent if the MSF is viewed solely as a means of analysing agenda-setting, but not decision-making).

Two papers which have gone furthest in trying to address these issues, are Natali (2004) and Ackrill and Kay (2011). Natali (2004: 1080) argues that policy entrepreneurs have the ability to help open windows, an idea that Corbett (2005) and, later, Ackrill and Kay, develop. This is important given the position of the Commission within EU structures. The policy entrepreneur can, as Ackrill and Kay show, be an individual within the Commission. On the other hand, the sole right of the Commission to propose legislation puts the organisation as a whole in a unique 
position regarding agenda-setting (although Peterson (1999) reports estimates that indicate, at that time, only between 10 and 25 percent of all EU legislative proposals began life in the Commission).

Furthermore, as also explored by Ackrill and Kay, the Commission is not a black box, but an organisation divided along thematic lines, across which many policy issues span. This can itself be a source of ambiguity. These authors thus build on the earlier work of Nugent and Saurugger (2002: 351), who spoke of institutional ambiguity creating 'boundary problems', where policy issues overlap different policy arenas.

As for the nature of windows of opportunity, Nugent and Saurugger (2002) introduced the notion of windows being open a bit or a lot - which, in turn, influences the magnitude of the policy changes that are then possible. Natali (2004: 1079) also raises the width of the window as an issue. That said, his prime focus is on seeking to understand when a window will open. Specifically, "variables do not float in the policy-making process, but combine with each other in a chain of events. A policy window is the result of an iterative process between problems, solutions, actors and events' Natali (2004: 1080). Ackrill and Kay (2011) took this idea in another direction, considering the length of time for which the window is open. Specifically, they consider situations where the window can be held open for a sustained period of time, thereby increasing the opportunities for decision-making to occur.

Such adaptations are not merely cosmetic, but have important implications for the MSF and its applicability to the study of EU policy processes. There is little disputing the fact that the EU, as an institutional structure, is highly complex and ambiguous (although in their analysis of the Lisbon Strategy, Borrás and Radaelli 
argue that, in policy areas relevant to the Strategy, the 2005 revision did go some way to clarifying the roles of Council and Commission).

A recent addition to the literature (Bache, forthcoming), utilises the MSF to look at an issue which, despite being very much part of policy discourse in recent years, has yet to receive policy attention. He analyses quality-of-life indicators as an input into public policy. Bache concludes that despite this idea receiving attention, it cannot yet be described as an idea whose time has come. Importantly, Bache identifies reasons why such measures have yet to yield policy responses. This is an important methodological contribution precisely because it improves our understanding of how the MSF can be applied to situations where there have not been policy responses to issues that, broadly speaking, have been identified as policy problems. Given the extent to which this issue has been attended to by politicians, it appears that a window of opportunity exists but which, for various technical and political reasons, has not resulted in a policy decision.

\section{Strengths and limitations}

\section{$\underline{\text { Strengths }}$}

While the MSF is valuable as a lens in organizing descriptions of EU policymaking processes, often unacknowledged is its contribution to meeting the challenge that confronts all temporally-orientated policy studies: how to abstract from particular historical contexts and identify the extent to which regularities across historical time and space endure. A motivating force behind the MSF is the search for causal regularities in the policy process whilst, at the same time, allowing for the explanatory influence of contingency. 
Although unexplored as yet in the EU policy process literature, there is potential for the MSF to be part of a fruitful dialogue with broader neo-institutionalist analysis in the study of EU policy-making. Notably, the MSF shares with institutionalism, especially the historical varieties, a stress on change being contingent on particular moments where the regular reproduction of patterns within institutionally complex environments is disrupted and reform moments present themselves. For example, the widely-held view that institutions are always vulnerable and there is nothing automatic about stability, recently outlined and extended in Mahoney and Thelen (2010), chimes with the insights of the MSF into the critical moments which contain reform potential.

In recent accounts of institutional change, active coalitions are required to underpin institutional stability. There are moments when institutions are vulnerable to adaptation, conversion and exhaustion. Change comes from shifts in coalitions resulting from the interaction between institutions in complex environments and changes in the level and extent of institutional compliance. These change mechanisms have a family resemblance - albeit distant - to disturbances in the problem or policy streams that provide part of the causal driving force in explanations within the MSF. Furthermore, the proposition that institutions are always incomplete, often overlapping and ambiguous is commonplace in several 'new' institutionalisms (see

\section{Doleys 2013 <THIS ISSUE: PUBLISHER TO ADD/UPDATE DETAILS AT}

PROOF $>$ ). This requires a more refined attention to historical causality that goes beyond the excessively deterministic work in which actors appear to be institutional 'dopes' responding blindly to the requirements of the institution.

The MSF holds the possibility for the theoretical accommodation and perhaps extension of these approaches by providing elements to apprehend shifts in actor 
preferences from outside the institutionalised policy environment, as well as changes in actor strategies which can result in change at critical moments. The account of agency in the MSF is potentially rich; actors are rational but operate in particular contexts, and their rationality must be understood in such situational terms. Actors are self-determining and motivations may range from external regulation through to intrinsic regulation, which express themselves in creative policy-making strategies.

In Barzelay and Gallego (2006), the MSF is interpreted as allowing the analytical separation of the broader context from the analysis of particular situations. The MSF requires scholars to be simultaneously sensitive to how spillovers and focussing events may lead to fleeting moments in on-going policy histories where reform potential exists, as well as understand the interaction between agents in such contexts at particular times. In such terms, the MSF is a mixture of the systemic and the situational and this is a major strength and novelty in the study of the EU policy process. Kingdon began the task of providing a set of causal mechanisms by which to explain contextual change in the US as well as providing insights into whether policy change opportunities are actually exploited and a policy proposal enjoys a strong probability of being agreed and implemented. The challenge for EU policy scholars is to translate and adapt the MSF as appropriate to analysing the EU context.

As discussed, the coupling of separate sub-policy processes, and the role of the policy entrepreneurs therein, is the important causal driver in the MSF. The coincidence of three streams at certain moments greatly increases the likelihood that a policy reform is enacted. The framework places the policy entrepreneur in a context but, in stressing ideational effort and conscious political activity, it reveals that the context is not wholly exogenous to the model. The MSF specifies agency a function of institutionalised roles, but that specification is not so determined as to preclude 
creativity, and actors' strategies that are unexpected and influential in upsetting institutional scripts. Put another way, the openness and fluidity in the policy process is balanced by the recognition that explanations of sequences of policymaking can only be satisfying if they examine how the specific policy-making situation is bounded by a historically contingent context, including both formal and informal institutions.

\section{$\underline{\text { Limitations }}$}

The limits of the MSF are in many respects consequent to its analytical novelty. It places the link between situations and broader context at the centre of understanding the EU policy process; yet the MSF remains limited in its ability so far to fully specify that link. The research agenda endures: how to understand policy entrepreneurs' situations in the broader context. Currently, much focus is on entrepreneurs as individuals with particular life experiences, aptitudes and policy preferences (see for example Corbett 2005). Such an analytical approach seemingly downplays the real ambition which girds the MSF: to illuminate the ceteris paribus clause for the comparative analysis of policy processes (Ackrill and Kay 2011). No entrepreneur alone will ever be enough to cause policy reform; we always require an account of the context. A ceteris paribus clause plays the role of fixing analytically the 'moment' replete with reform possibility. This facilitates claims such as 'this policy entrepreneurial strategy in this situation is successful only in this particular context'. If context changes in another case or over time - i.e. everything is not equal then we cannot infer the same entrepreneurial causal mechanism will lead to reform. The expert and skilled advocacy of a policy idea, or skilled brokering, in one context does not produce reform; but exactly the same idea and brokering in a different 
context does produces reform. This is the causal structure behind the maxim that 'ideas have their time.'

There is an additional ideational mechanism connecting the three streams that is hinted at but not really developed in the MSF literature. The emergence of ideas within the policy stream may be considered analogous to natural selection: policy ideas circulate, combine and recombine in the garbage can but are selected by an environment of technical feasibility, value congruence, budgetary implications, and political support. In this case, conditions of issue complexity can select certain proposals from within the policy stream; and policy change occurs in response to the nature of the policy window, as opposed to the advocacy or brokering entrepreneurial mechanisms where the policy window simply provides an opportunity for coupling. In this mechanism, the policy issue which is salient in the window may be of such complexity as to demand a unique solution or, at least, the number of policy solutions are so highly circumscribed that it is the nature of the window that does much of the explanatory heavy lifting, as opposed to entrepreneurial agency.

This variation in policy windows is an important challenge for future research using the MSF in the EU context. In particular, for the concept of windows of opportunity to provide analytical leverage within the MSF framework it must escape the circular logic that all episodes of reform are windows of opportunity, and that what characterises a window of opportunity is evidence of policy change. The challenge for scholars is to distinguish, theoretically and empirically, non-change windows from those that result in change windows. Theoretical work on windows of opportunity where change or reforms do not eventuate is limited; as is sustained empirical analysis which recreates through counterfactual reasoning moments where reform possibility appears to exist but where no reforms are observed. Without a 
convincing account of failed opportunities, the MSF will be limited in both the range of policy processes it can account for as well as the explanatory power it can offer in the causal reconstruction of policy-making episodes.

As noted, coupling is the critical element in the MSF and is a function of both the nature of the policy window and the skills and resources of the policy entrepreneur. However, almost all the literature focuses on the latter element rather than the first. In the original Kingdon model, the streams are independent and thus the opening of a window in either the politics or problem streams is not causally related to the policy stream. Instead, the policy stream is a transmission belt of previous policy decisions, policy analyses and the nature of the policy discourse. Within the stream there are networks of policy entrepreneurs who mediate the emergence of policy ideas and attempt to increase the receptivity of policy-makers to their ideas.

Importantly, what emerges as a potential solution in response to the opening of a policy window is the result of prior advocacy for ideas and proposals by entrepreneurs, in particular their skill, persistence and resources in pushing particular project. For MSF applications to the EU, it is their ability to sell these ideas to policy makers in response to policy windows - and thereby couple the politics, problems and policy streams - that explains whether windows of policy opportunity actually result in policy change.

However, this account of coupling fails to capture the intuition in broader policy scholarship of a mood of 'something needing to be done'. In a manner consistent with MSF insights into situations where policy solutions exist in search of a problem or rationale, there is the logical possibility that agendas may be used by policy makers to search out proposals. When these windows occur in the political stream, the agenda may be short term or symbolic, forcing a search for politically 
successful policies. These are not obviously related to solving policy problems and the MSF contains no presumption of rationality in the policy process. Policy may be decided by the coupling of the politics and policy streams, which subsequently drives a search for elements in the problem stream that might serve to legitimise the alreadydecided policy.

In the case of windows creating short term, time-pressured political agendas which act as filter mechanisms for ideas in the policy stream, the role for policy entrepreneurs becomes limited. They still advocate and keep ideas available for selection by policy-makers driven by short term political pressures, but their brokerage role is bounded in explaining when, why and in what form policy change is enacted. Instead, it is the nature of the policy window and the reform agenda it creates for policy-makers which plays the primary causal role in shaping which policy ideas gain attention.

This however leads back us back to the limits of the MSF. For example, Corbett (2005) locates policy entrepreneurs in the higher levels of the Commission. This is perfectly reasonable for the study of EU policy processes, but in doing so the distinction between policy entrepreneurs and policy makers in the politics stream becomes blurred. Furthermore, for Corbett it is essential to appreciate that these are individuals with life histories, personal beliefs, identities as well as an institutional position. Thus you must understand them, beyond just their institutional context to apprehend fully their influence in policy change.

This is indubitably true, but it leaves us with a research agenda about policy entrepreneurship: why do some succeed and others fail in different contexts? Why are some able to discern and exploit opportunities and others not? To the extent that the effectiveness of policy entrepreneurs is a function of institutional position, what does 
the concept add? Does the term mean anything without analysis of the particular situation in which opportunities occur (i.e., entrepreneurship qua actions can only be judged in a particular situation)?

There is a further alternative mechanism that focuses on a policy window in either the politics or problem stream forcing or enabling policy-makers to search for solutions. Instead of passive agents who are sold coupling strategies by policy entrepreneurs, or bound by issue complexity to a highly circumscribed set of policy options, they employ intentional selection mechanisms to select a policy solution that is appropriate for the nature of the agenda set by the policy window. Thus policy solutions can make it onto the decision-agenda not because they are sold by the persistence and skill of policy entrepreneurs but rather because policy makers select the ideas (as appropriate for the policy window) and thus the policy entrepreneurs who advocate. This alternative specification further limits in the concept of policy entrepreneurship: most pertinently, are those whom we have hitherto called policymakers actually policy entrepreneurs?

In the MSF literature, the answer is ambiguous. For some, policy entrepreneurs sit outside the formal decision-making process. However, as noted above subsequent scholarship (particularly in applications to the EU) has also placed policy entrepreneurs in senior bureaucratic positions. If policy entrepreneurs can be in high formal office as well as outside the formal machinery of policy making, then the policy entrepreneurship concept is stretched. Doing so conflates two separate mechanisms in policy making: the selling of ideas to policy makers and the selecting of ideas by policy makers. Both may be entrepreneurial. One suggestion is to understand entrepreneurship as a general label for a set of behaviours in the policy process, rather than a permanent characteristic of an individual or a particular role. On 
this argument, entrepreneurs can be from anywhere and the challenge is to distinguish those policy-makers who play their institutional role from those who qualify as entrepreneurs in particular reform episodes. The attribution of causality to agency qua policy entrepreneurship is only ever temporary and acutely sensitive to the particular context and situation.

The discussion of entrepreneurship in EU policy-making tends to rely on the unstated argument that entrepreneurial characteristics at the individual level are not normally distributed in the population; there is something distinctive about the individuals who are policy entrepreneurs. However, this attribution is always done $e x$ post and always to political actors involved in actual reform. Our understanding of policy entrepreneurship thus becomes significantly limited. For instance, we have no analytical means of explaining successful entrepreneurship because we have no sample of failed entrepreneurial strategies. Perhaps more importantly, we equate successful entrepreneurship with actual reform, but what about agency in defence of the status quo? There are various strategies employed by actors to preserve institutions and policy systems against reform strategies. Therefore, we can only really explain entrepreneurship in terms of actions in a particular context. This is perhaps better expressed as policy entrepreneurship not being a stable characteristic that differentiates policy agents in all situations; but rather as referring to actions in certain policy-making situations.

The implication of placing EU issue and institutional complexity at the heart of the development of frameworks for the analysis of the EU policy process is that any framework or lens, individually, will be incomplete. The acknowledgement of complexity as the central feature of life in the EU undermines any search for a general theory of EU policy-making. Pluralism rather than monism underpins the intellectual 
project of this collection. The MSF contributes much to this endeavor in its ability to complement other approaches, most particularly those which provide accounts of the causal logic of institutional variables. The MSF analysis privileges links between the broader contextual regularities and patterns, and situational moments of contingency where policy-making processes may end up heading in unexpected and unpredictable directions. The three streams, their coupling, and the role of agency therein provide analytical leverage on periods of relative policy stability as well as specific moments where things are open to change.

As it stands, the MSF is not formally articulated as a theory or model that might allow empirical testing of its predictive accuracy. Indeed, it is moot whether this is a desirable ambition for a framework whose strongest empirical achievements to date have been to offer temporally-orientated perspectives on EU policy. It may be more productive to develop the MSF in conjunction with other EU policy process approaches explored here, rather than as a competitor. This kind of pluralism suggests that although different lenses might be rivalrous in the analysis of any particular reform episode, under similar conditions they may be additive rather in terms of overall explanatory power available for apprehending highly specific combinations of causal mechanisms across time and different EU policy sectors. Pragmatist philosopher C. S. Pierce argues that different frameworks should be viewed as strands braided together into a rope, instead of links in a chain. With links in a chain, if there is even one weak link it does not matter whether different approaches are competitive or complementary in any particular instance. However, while individual strands in a rope may not be strong enough to support the explanatory weight for which they are needed, they may be stronger when braided together. 


\section{Where do we go from here?}

The MSF has proven useful in identifying and helping to resolve puzzles of EU policy processes and policy-making. Its usefulness lies in the lens' capacity to handle ambiguity and its ability to capture the complex interactions among institutions, issues, and entrepreneurs. This has particular resonance in the EU case, with its unique and highly complex multi-level decision-making process. However, as we argued above, the MSF's novelty is also its limitation. The focus on context and agency is an important but analytically difficult enterprise because it demands access to significant amounts of information to explain without the promise of corresponding ability to predict. To be sure, MSF incorporates randomness into the explanation so it cannot predict which individual events or outcomes will occur. But it can generate expectations that increase the likelihood of some outcomes occurring and not others. Clarifying causal drivers and specifying testable hypotheses will go a long way toward augmenting explanatory power and enhancing our understanding of probabilistic expectations.

Research clarifying the lens' internal causal drivers and hypotheses, undertaken in recent papers through reflection on the MSF in the EU context, offers considerable promise for future research. Recent work has begun to enhance our understanding of both agenda-setting and decision-making; of the distinction between policy entrepreneurs as individuals and policy entrepreneurship as a process; of 'boundary problems' - policy spillovers potentially being endogenous as well as exogenous - and of the implications of that distinction for policy-making; and of policy entrepreneurs participating in decision-making and opening policy windows. These developments are important because they give the MSF greater nuance and sophistication. 
We do not argue that a singular, universal, multiple streams lens can be developed for use in all EU circumstances; adaptation of the lens may be required. But this is an essential feature of the MSF and why it is so well-suited to applications where agenda-setting and decision-making are replete with ambiguities. Clarification of the lens' internal causal drivers and their adaptation to the EU context hold considerable promise for future research. For example, the EU's institutional context and varying timescapes are uniquely suited to further specification of coupling as an institutional venue-shopping strategy. Under what conditions do hierarchical vs nonhierarchical institutional arrangements promote venue-shopping and success? How do policy windows influence the 'shopping' process? Links with the literature on punctuated equilibria (Princen 2013 <THIS ISSUE: PUBLISHER TO

ADD/UPDATE DETAILS AT PROOF>) and multi-level governance (Stephenson 2013 <THIS ISSUE: PUBLISHER TO ADD/UPDATE DETAILS AT PROOF>) may provide fruitful collaborative research in these areas. Given the proclivity of EU mechanisms for cooperation and for limiting conflict, how do frame contests work across issues? Daviter (2011) provides some examples from the biotechnology field, but more work needs to be done to capture fully the conditions of entrepreneurial success and its interaction with broader political forces, including the presence or absence of a 'European' mood, which is a concept that features prominently in national applications of the MSF (e.g., Kingdon 1995).

Another feature of the MSF lens which makes it suitable to application to the EU context is its fluidity. The three streams not only ebb and flow in relation to each other but, in so doing, transverse and connect different levels of policy actors. EU policy-making processes are relatively stable, but actor participation in policy-making is fluid and the policy issues considered at the EU level is growing. The deliberately 
loose coupling between means and ends, choice and implementation, what Héritier (1999) calls the strategy of subterfuge, has served member states well so far. However, an expansion of EU policy competences increasingly implies s member states are giving up sole jurisdiction over a range of policy issues. At the same time, there continue to be debates over the extent to which the EU suffers from a democratic deficit (e.g., Moravcsik 2002; Crombez 2003).

The MSF predicts political conflict will rise, increasing the importance of policy entrepreneurs and their strategies. At the same time, democratic accountability through representation remains unchanged even if some cosmetic changes are made, such as the proposal to elect the President of the Commission through popular elections. A major task for the MSF is to specify channels of democratic accountability in light of increasing complexity and political acrimony. Does greater EU institutional complexity actually increase democratic accountability and transparency or does the presence of more institutional venues give rise to more opportunities for political manipulation and lower transparency?

Institutional and issue complexity amplify dramatically through jurisdictional overlap, while accountability is diffused among multiple institutions and actors. One may view such developments as increasing the potential number of policy windows available for entrepreneurs to push through pet proposals that apply throughout the EU, but for which groups of voters have little input. Assuming the distribution of timescapes does not change dramatically, the likelihood of such opportunities will multiply, intensifying political manipulation struggles. As Krause (2003) implies in his study of the CFSP, there are, quite simply, an expanding number of areas of EU activity to which the MSF can be applied. Any takers? 
Biographical Notes: Robert Ackrill is Professor of European Economics and Policy at Nottingham Business School, UK. Adrian Kay is an Associate Professor in the Crawford School of Economics and Government at the Australian National University.

Addresses for correspondence: Professor Robert Ackrill, Division of Economics, Nottingham Business School, Nottingham Trent University, Burton Street, Nottingham, NG1 4BU, UK. email: robert.ackrill@ntu.ac.uk. Dr Adrian Kay, Associate Professor, Crawford School of Public Policy, Crawford Building, No. 132 Lennox Crossing, The Australian National University, Canberra ACT 0200, Australia. email: adrian.kay@anu.edu.au.

\section{References}

Ackrill, R. and Kay, A. (2011) 'Multiple streams in EU policy-making: the case of the 2005 sugar reform', Journal of European Public Policy 18(1): 72-89.

Alpaslan, C.M. and Mitroff, I.I. (2011) Swans, swine, and swindlers, Stanford: Stanford University Press.

Bache, I. (forthcoming) 'Measuring quality of life for public policy: an idea whose time has come? Agenda-setting dynamics in the European Union', Journal of European Public Policy.

Barzelay, M. and Gallego, R. (2006) 'From "new institutionalism" to "institutional processualism": advancing knowledge about public management policy change', Governance 19(4): 531-57.

Baumgartner, F. and Jones, B. (1993) Agendas and instability in American politics, Chicago: University of Chicago Press. 
Birkland, T.A. (1997) After disaster: agenda-setting, public policy and focusing events, Washington, DC: Georgetown University Press.

Borrás, S. and Radaelli, C.M. (2011) 'The politics of governance architecture: creation, change and effects of the EU Lisbon Strategy', Journal of European Public Policy 18(4): 463-84.

Cohen, M.D., March, J.G. and Olsen, J.P. (1972) 'A garbage can model of organizational choice', Administrative Science Quarterly 17: 1-25.

Corbett, A. (2005) Universities and the Europe of knowledge: ideas, institutions and policy entrepreneurship in European Union higher education policy, 1955-2005, Basingstoke: Palgrave Macmillan.

Cram, L. (2001) 'Whither the Commission? reform, renewal and the issue-attention cycle', Journal of European Public Policy 8(5): 770-86.

Crombez, C. (2003) 'The democratic deficit in the European Union: much ado about nothing'? European Union Politics 4(1): 101-20.

Daviter, F. (2011) Policy-framing in the European Union, Basingstoke: Palgrave Macmillan.

Doleys, T. (2013) <THIS ISSUE: PUBLISHER TO ADD/UPDATE DETAILS AT PROOF>

Eberlein, B. and Radaelli, C.M. (2010) 'Mechanisms of conflict management in EU regulatory policy', Public Administration 88(3): 782-99.

Goetz, K.H. (2009) 'How does the EU tick? five propositions on political time', Journal of European Public Policy 16(2): 202-20.

Héritier, A. (1999) Policy-making and diversity in Europe, Cambridge: Cambridge University Press. 
Jordan, A., Wurzel, R., Zito, A.R. and Brückner, L. (2003) ‘European governance and the transfer of 'new' environmental policy instruments (NEPIs) in the European Union', Public Administration 81(3): 555-74.

Keeler, J. (1993) 'Opening the window for reform', Comparative Political Studies 25(4): 433-86.

Krause, A. (2003) 'The European Union's Africa policy: the Commission as policy entrepreneur in the CFSP', European Foreign Affairs Review 8: 221-37.

Kingdon, J. (1995) Agendas, alternatives and public policies, $2^{\text {nd }}$ ed, New York: Harper Collins.

Mahoney, J. and Thelen, K. (eds) (2010) Explaining institutional change: ambiguity, agency, and power, Cambridge: Cambridge University Press.

March, J. (1978) 'Bounded rationality, ambiguity and the engineering of choice', Bell Journal of Economics 9: 587-608.

March, J. (1994) A Primer on decision-making, New York: Free Press.

Mintrom, M. and Norman, P. (2009) 'Policy entrepreneurship and policy change', Policy Studies Journal 37(4): 649-67.

Moravcsik, A. (2002) 'In defence of the 'democratic deficit': reassessing legitimacy in the European Union', Journal of Common Market Studies 40(4): 603-24.

Natali, D. (2004) 'Europeanization, policy arenas, and creative opportunism: the politics of welfare state reforms in Italy', Journal of European Public Policy 11(6): $1077-95$

Nowak, T. (2010) 'Of garbage cans and rulings: judgements of the European Court of Justice in the EU Legislative Process', West European Politics 33(4): 753-69. 
Nugent, N. and Saurugger, S. (2002) 'Organizational structuring: the case of the European Commission and its external policy responsibilities', Journal of European Public Policy 9(3): 345-64.

Olsen, J.P. (2001) 'Garbage cans, new institutionalism, and the study of politics', American Political Science Review 95(1): 191-98.

Peterson, J. (1999) 'The Santer Era: the European Commission in normative, historical and theoretical perspective', Journal of European Public Policy 6(1): 4665.

Pollack, M.A. (1997) 'Delegation, agency, and agenda setting in the European Community', International Organization 51(1): 99-134.

Princen, S. (2007) 'Agenda-setting in the European Union: a theoretical exploration and agenda for research', Journal of European Public Policy 14(1): 21-38.

Princen, S. (2013) <THIS ISSUE: PUBLISHER TO ADD/UPDATE DETAILS AT PROOF>

Ringe, N. (2005) 'Policy preference formation in legislative politics: structures, actors, and focal points', American Journal of Political Science 49(4): 731-45.

Stephenson, P. (2013) <THIS ISSUE: PUBLISHER TO ADD/UPDATE DETAILS AT PROOF>

Winn, N. (1998) 'Who gets what, when, and how? The contest conceptual and disciplinary nature of governance and policy-making in the European Union', Politics 18(2): 119-32.

Zahariadis, N. (2003) Ambiguity and choice in public policy: political manipulation in democratic societies, Washington, DC: Georgetown University Press. 
Zahariadis, N. (2007) 'The multiple streams framework: structure, limitations, prospects', in P.A. Sabatier (ed.), Theories of the Policy Process, 2nd edn, Boulder, CO: Westview Press, pp. 65-92.

Zahariadis, N. (2008) 'Ambiguity and choice in European public policy', Journal of European Public Policy 15(4): 514-30.

Zahariadis, N. (2012) 'Complexity, coupling, and policy effectiveness: the European response to the Greek sovereign debt crisis', Journal of Public Policy 32(2): 99116.

Wordcount, all-in, is 